\title{
Effect of $\alpha$ - and $\beta-H / F$ substitution on the homolytic bond strength in dormant species of controlled radical polymerization: OMRP vs. ITP and RAFT
}

\section{Rinaldo Poli, ${ }^{* a, b}$ S. M. Wahidur Rahaman, ${ }^{a}$ Vincent Ladmiral, ${ }^{c}$ Bruno Ameduri ${ }^{c}$}

${ }^{a}$ CNRS, LCC (Laboratoire de Chimie de Coordination), Université de Toulouse, UPS, INPT, 205 route de Narbonne, BP 44099, F-31077 Toulouse Cedex 4, France CNRS. Fax: +33-561553003; Tel: +33-561333174; E-mail:rinaldo.poli@lcc-toulouse.fr.

${ }^{b}$ Institut Universitaire de France, 1, rue Descartes, 75231 Paris Cedex 05, France.

${ }^{c}$ Ingénierie et Architectures Macromoléculaires, Institut Charles Gerhardt, UMR 5253 CNRS, UM, ENSCM, Place Eugène Bataillon, 34095 Montpellier Cedex 5, France

\section{Abstract}

The $\mathrm{X}-\mathrm{C}$ bond dissociation energies (BDEs) for five series of $\mathrm{X}-\mathrm{CH}_{2-n} \mathrm{~F}_{n} \mathrm{CH}_{3-m} \mathrm{~F}_{m}$ molecules $(n=$ $0,1,2 ; m=0,1,2,3)$ with $\mathrm{X}=\mathrm{H}, \mathrm{I}, \mathrm{SC}(\mathrm{S}) \mathrm{OEt}, \mathrm{Co}(\mathrm{acac})_{2}$ or $\mathrm{Mn}(\mathrm{CO})_{5}$ were calculated using a DFT approach, yielding results in good agreement with the few experimentally determined values $(\mathrm{X}=$ $\mathrm{H}$ and I). Calculations were also carried out on the simpler $(\mathrm{CO})_{5} \mathrm{Mn}_{-}-\mathrm{CF}_{n} \mathrm{H}_{3-n}$ molecules $(n=0,1$, $2,3)$, for which experimental data are available. The BDE trends as $n$ and $m$ vary are different for different $\mathrm{X}$ groups: BDE increases as $n$ increases (particularly from 0 to 1 ) for $\mathrm{X}=\mathrm{H}$, I and $\mathrm{SC}(\mathrm{S}) \mathrm{OEt}$, but decreases (particularly from 1 to 2 ) for $\mathrm{X}=\mathrm{Co}(\mathrm{acac})_{2}$ and $\mathrm{Mn}(\mathrm{CO})_{5}$. The effective charge analysis suggests that the effect of the bond polarity on the ionic component of the bond energy is a major contriution to these trends. These results rationalize the limited control, for the polymerization of vinylidene fluoride (VDF), by the iodine transfer polymerization (ITP) and reversible addition-fragmentation chain-transfer (RAFT) polymerization approaches. They also predict a better controlled process for this monomer by organometallic mediated radical polymerization (OMRP), mediated by $\mathrm{Co}(\mathrm{acac})_{2}$. They also allow predictions for the performance of the same processes for other fluorinated monomers. The results for $\mathrm{X}=\mathrm{Mn}(\mathrm{CO})_{5}$ suggest that the $(\mathrm{CO})_{5} \mathrm{Mn}-\mathrm{CH}_{2-n} \mathrm{~F}_{n} \mathrm{CH}_{3-m} \mathrm{~F}_{m}$ molecules cannot be thermally activated at significant rates. Therefore, they either do not form or are photochemically reactivated during the $\mathrm{Mn}_{2}(\mathrm{CO})_{10}$-assisted ITP polymerization of VDF. 
Keywords: DFT calculations, organometallic-mediated radical polymerization, iodine transfer polymerization, RAFT polymerization, vinylidene fluoride, cobalt, manganese.

\section{Introduction}

Reversible Deactivation Radical Polymerization (RDRP), also commonly known as Controlled Radical Polymerization (CRP), has now become a preferred tool for the fabrication of functional polymers by macromolecular engineering. It gives access to chain-end-functionalized macromolecules with precisely controlled architectures under mild conditions for a wide variety of monomers and is compatible with a variety of reaction media, including water. One of the outstanding challenges in this area is to find better ways to control the polymerization of less reactive monomers, in particular fluorinated olefins such as vinylidene fluoride $\left(\mathrm{VDF}, \mathrm{CH}_{2}=\mathrm{CF}_{2}\right)$, trifluoroethylene $\left(\mathrm{TrFE}, \mathrm{CHF}=\mathrm{CF}_{2}\right)$ or tetrafluoroethylene $\left(\mathrm{TFE}, \mathrm{CF}_{2}=\mathrm{CF}_{2}\right)$. This is of interest because the chemical inertness and physical properties of these polymers, in combination with selfassembly when segments of these polymers are incorporated in block-like architectures, opens access to a variety of new materials for advanced applications $[1,2]$.

VDF has attracted greater attention than other fluorinated monomers. Its RDRP has first been achieved by Iodine Transfer Polymerization (ITP), which is a degenerate transfer method based on the associative exchange of growing radical chains with iodine-capped dormant chains [3]. Indeed, the ITP of VDF is one of the first implemented RDRP method, pioneered by the Daikin company in the late 70s [4-6], which has already marketed thermoplastic elastomers based on this monomer for over 20 years. More recently, a reasonably good control has also been achieved by the Reversible Addition-Fragmentation chain-Transfer (RAFT) polymerization technique [7-12]. This monomer is 
asymmetric and has a non-negligible probability to add to the growing radical chain in either the "normal" mode, yielding a PVDF- $\mathrm{CH}_{2} \mathrm{CF}_{2}$ (head, $\mathrm{PVDF}_{\mathrm{H}}$ ) chain end, or the "inverted" mode, yielding a PVDF- $\mathrm{CF}_{2} \mathrm{CH}_{2}{ }^{\cdot}$ (tail, $\mathrm{PVDF}_{\mathrm{T}}{ }^{\circ}$ ) chain end. Therefore, the reversible deactivation of the growing $\mathrm{PVDF}^{*}$ chain by a moderating agent $\mathrm{X}$ yields two different types of dormant chains, $\mathrm{PVDF}_{\mathrm{H}} \mathrm{X}$ and $\mathrm{PVDF}_{\mathrm{T}} \mathrm{X}$. The same phenomenon occurs for other asymmetric monomers if their polymerization is affected by inverted monomer addition. It is one of the main reasons for the loss of control during the VDF polymerization by ITP and RAFT, because the two relevant $\mathrm{C}-\mathrm{X}$ bonds (X = I in ITP, SC(S)OEt in RAFT) have different homolytic bond strengths. Specifically, the occasionally generated $\mathrm{PVDF}_{\mathrm{T}} \mathrm{X}$ species is reactivated less easily, thus the tail chain ends accumulate in the reaction medium leading to a slowdown of the degenerative transfer between the active radical chains and the domant chains and to a broadening of the molecular weight distribution. In recent work [13], DFT calculations have confirmed that the C-S bond in $\mathrm{HCF}_{2} \mathrm{CH}_{2}-\mathrm{SC}(\mathrm{S}) \mathrm{OMe}$, a model of $\mathrm{PVDF}_{\mathrm{T}}-\mathrm{SC}(\mathrm{S}) \mathrm{OEt}$, is significantly stronger than that in $\mathrm{CH}_{3} \mathrm{CF}_{2}-\mathrm{SC}(\mathrm{S}) \mathrm{OMe}$, which is a model of $\mathrm{PVDF}_{\mathrm{H}-\mathrm{SC}}(\mathrm{S}) \mathrm{OEt}$.

It is of interest to consider the possible application of organometallic-mediated radical polymerization (OMRP), particularly with a simple complex such as $\left[\mathrm{Co}(\mathrm{acac})_{2}\right]$ (where acac stands for acetylacetonate), to fluorinated olefins such as VDF, because this moderating agent was shown efficient in the controlled polymerization of less reactive monomers including vinyl acetate [14-16] and ethylene [17]. In addition, it is also of interest to learn about the homolytic bond strength in $(\mathrm{CO})_{5} \mathrm{Mn}-\mathrm{R}$ compounds $(\mathrm{R}=$ fluorinated alkyl). Asandei and coworkers [18, 19] have shown that $(\mathrm{CO})_{5} \mathrm{Mn}^{\bullet}$ radicals, generated by visible light photolysis of $\mathrm{Mn}_{2}(\mathrm{CO})_{10}$, are able to reactivate both $\mathrm{PVDF}_{\mathrm{T}}-\mathrm{I}$ and $\mathrm{PVDF}_{\mathrm{H}} \mathrm{I}$ dormant chains in ITP with formation of $(\mathrm{CO})_{5} \mathrm{MnI}$, thus taming the abovementioned slowdown problem. However, the possible direct $\mathrm{PVDF}^{\bullet}$ trapping by $(\mathrm{CO})_{5} \mathrm{Mn}{ }^{\bullet}$ to generate $(\mathrm{CO})_{5} \mathrm{Mn}-\mathrm{PVDF}$, namely the dormant chains of a hypothetical OMRP controlling mechanism, has not been considered in detail and thus the possible implication of these organometallic dormant chains in the $\mathrm{Mn}_{2}(\mathrm{CO})_{10}$-assisted ITP of VDF remains a question. 
This contribution aims at studying the $\mathrm{R}-\mathrm{X}$ bond strength for $\mathrm{X}=\mathrm{Co}(\mathrm{acac})_{2}$ and $\mathrm{Mn}(\mathrm{CO})_{5}$, as a function of the number of $\mathrm{F}$ substituents in the $\alpha$ and $\beta$ position, namely $\mathrm{R}=\mathrm{CH}_{2-n} \mathrm{~F}_{n} \mathrm{CH}_{3-m} \mathrm{~F}_{m}(n=$ $0,1,2 ; m=0,1,2,3)$ by using the computational approach. For comparison, the bond strengths for the corresponding R-I and R-SC(S)OMe systems, models of the dormant species in ITP and xanthate-based RAFT have also been investigated for the first time for the full series of $\mathrm{F}$ substitution at the $\alpha$ and $\beta$ positions $(n=0,1,2 ; m=0,1,2,3)$. The R-H systems, for which a number of experimental BDE data are available, have also been calculated at the same level of theory for benchmarking purposes. The results of this study serve as a predicting tool for the development of efficient mediating agents for the RDRP of VDF and other fluorinated monomers.

\section{Computational Details}

The computational work was carried out using the Gaussian09 suite of programs [20]. Gas-phase geometry optimizations were performed without any symmetry constraint using the BPW91* functional [21] and the 6-31G(d,p) basis functions for all light atoms $(\mathrm{H}, \mathrm{C}, \mathrm{F}, \mathrm{O}, \mathrm{S})$, whereas the $\mathrm{Mn}, \mathrm{Co}$ and I atoms were treated with the SDD basis set augmented by an $\mathrm{f}$ polarization function ( $\alpha$ $=2.195$ for $\mathrm{Mn}, 2.780$ for $\mathrm{Co})$ [22] of a d polarization function $(\alpha=0.289$ for I) [23]. The unrestricted formulation was used for open-shell molecules, yielding only minor spin contamination $\left(<S^{2}\right\rangle$ at convergence was very close to the expected value of 0.75 for the radical species and 3.75 for the spin quartet species). All final geometries were characterized as local minima by verifying that all second derivatives of the energy were positive. Thermochemical corrections were obtained at 298.15 K on the basis of frequency calculations, using the standard approximations (ideal gas, rigid rotor and harmonic oscillator). Corrections for dispersion were carried out at the fixed BPW91* optimized geometries using Grimme's D3 empirical method (BPW91*-D3) with SR6 and S8 parameters identical to those optimized for B3PW91 [24]. 


\section{Results}

All calculations were conducted with the BPW91* functional, which is a modified version of B3PW91 in which the c3 coefficient in Becke's original three-parameter fit to thermochemical data was changed to 0.15 [21]. This functional was shown to yield better performance for light transition metals where the spin state changes from reactants to products, relative to pure functionals such as BP86 that tend to overestimate the relative stability of the low spin state, and relative to hybrid functionals such as B3PW91 that tend to overestimate the relative stability of the high spin state. The bond dissociation enthalpies (BDEs) or R-X were obtained by difference between the enthalpies of gas phase optimized RX on one side and the sum or separated R and X on the other side. Although our main focus is not the faithful reproduction of experimentally determined BDEs, which are at any rate unavailable for most of the metal systems addressed by the present investigation, benchmarking with the available R-H and R-I BDEs indicate reasonable quantitative agreement (vide infra). Since information on trends of homolytic bond strengths is sought for series of homologous compounds, the adopted approach is believed to be suitable because any systematic error related to the possible inadequacy of the method should remain more or less constant along the series of reported values. The effect of dispersion forces will be examined by comparing the results in the absence and presence of a correction based on Grimme's D3 method [24]. The Cartesian coordinates of all optimized geometries are provided in the Supporting Information.

\section{(a) Organic radicals and BDE of the R-H bonds.}

The full list of $\mathrm{CH}_{2-n} \mathrm{~F}_{n} \mathrm{CH}_{3-m} \mathrm{~F}_{m}$ radicals has been previously investigated computationally [2528] with focus on the structure, rotational barriers, vibrational frequencies and thermodynamic functions. The BDEs of the corresponding $\mathrm{H}_{-}-\mathrm{CH}_{2-n} \mathrm{~F}_{n} \mathrm{CH}_{3-m} \mathrm{~F}_{m}$ bonds have already been computed with geometry optimizations at the MP2//6-31G(d,p) level and MP2//6-311G(d,p) energies at the fixed MP2//6-31G(d,p) optimized geometries [29]. The trends observed at our level of theory are essentially the same and will not be commented. Highlights on the radical geometries and energies 
are provided in the SI (Tables S1-S3). Figure 1 summarizes the computed BDE trends and a comparison with the previous calculations [29] is shown Figure S1. Our calculations appear in better agreement with the availale thermochemical data, since the BDE of $\mathrm{H}-\mathrm{CH}_{2} \mathrm{CH}_{3}, \mathrm{H}-\mathrm{CH}_{2} \mathrm{CF}_{3} \mathrm{H}-$ $\mathrm{CF}_{2} \mathrm{CH}_{3}$ and $\mathrm{H}-\mathrm{CF}_{2} \mathrm{CF}_{3}$ have been reported $[30,31]$ as $101.1 \pm 1.0$ (cf. 100.6), 106.7 \pm 1.0 (cf. 105.3), $99.5 \pm 2.5$ (cf. 97.6) and $102.7 \pm 0.5$ (cf. 99.9) $\mathrm{kcal} / \mathrm{mol}$, respectively. The D3 dispersion correction increases the BDE values by amounts varying from $0.4 \mathrm{kcal} / \mathrm{mol}$ for $\mathrm{H}-\mathrm{CH}_{2} \mathrm{CH}_{3}$ to $0.9 \mathrm{kcal} / \mathrm{mol}$ for $\mathrm{H}-\mathrm{CF}_{2} \mathrm{CF}_{3}$ and thus improves the agreement with the experimental data.

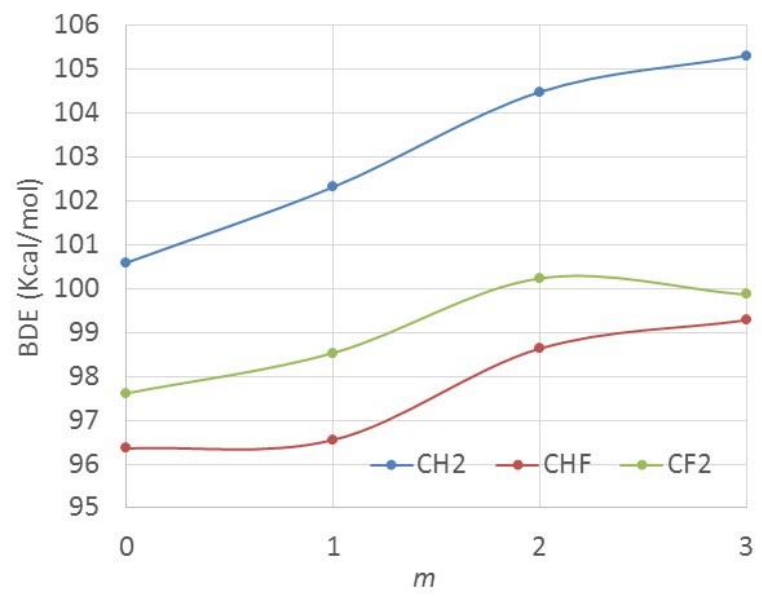

Figure 1. C-H bond dissociation enthalpies $(\mathrm{kcal} / \mathrm{mol})$ for $\mathrm{H}_{-} \mathrm{CF}_{n} \mathrm{H}_{2-n} \mathrm{CF}_{m} \mathrm{H}_{3-m}(n=0,1,2 ; m=0$, $1,2,3)$. The reported values are the calculated dispersion-corrected $\Delta \mathrm{H}$ values.

As already commented in previous contributions $[29,30]$, the BDE depends on the number of $\mathrm{F}$ atoms located on both the $\alpha$ and the $\beta-\mathrm{C}$ atoms. For molecules with an identical substitution at the $\beta \mathrm{C}$ atom, the $\mathrm{BDE}$ is strongest when generating a $\mathrm{CH}_{2}$-based radical. It decreases on going to the CHF-based radical, but then slightly increases on going from $\mathrm{CHF}$ to $\mathrm{CF}_{2}$. For the molecules generating the $\mathrm{CH}_{2}$ radical, the BDE increases substantially upon increasing the number of $\beta-\mathrm{F}$ atoms, whereas the other two series show non-monotonous changes with a slight global tendency for a bond strength increase. As previously pointed out [30], the strong and opposing $\sigma$-withdrawing and $\pi$-donating electronic effects of the $\mathrm{F}$ atoms and the lack of additivity of multiple $\mathrm{H} / \mathrm{F}$ substitutions make the net effect difficult to predict and rationalize. 


\section{(b) BDE of the R-I bonds.}

Calculations analogous to those reported in the previous sections have been carried out on the I$\mathrm{CH}_{2-n} \mathrm{~F}_{n} \mathrm{CH}_{3-m} \mathrm{~F}_{m}$ molecules, in order to derive the I-C BDE, which is relevant for the controlled polymerization of fluorinated alkenes by ITP. The full results are provided in the SI (Table S4) and the BDEs are summarized in Figure 2. The dispersion correction is slightly greater than in the case of the R-H molecules, resulting in a BDE increase in the range from $2.8 \mathrm{kcal} / \mathrm{mol}$ for $\mathrm{I}-\mathrm{CH}_{2} \mathrm{CH}_{3}$ to $4.2 \mathrm{kcal} / \mathrm{mol}$ for $\mathrm{I}_{-} \mathrm{CF}_{2} \mathrm{CF}_{3}$ and $\mathrm{I}_{-} \mathrm{CF}_{2} \mathrm{CHF}_{2}$. The calculated parameters are in relatively good agreement with the few experimentally determined BDEs $\left(\mathrm{I}-\mathrm{CH}_{2} \mathrm{CF}_{3}: 56.3 \pm 1.0 \mathrm{kcal} / \mathrm{mol}\right.$ [32]; I-

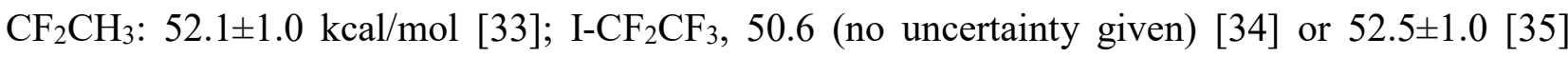
$\mathrm{kcal} / \mathrm{mol}$ ). The agreement is better without consideration of the D3 dispersion correction for the first two compounds, but with the correction for the last one $(55.7,53.2$ and $49.8 \mathrm{kcal} / \mathrm{mol}$, respectively, vs. $57.7,55.2$ and $51.8 \mathrm{kcal} / \mathrm{mol}$ with the correction).

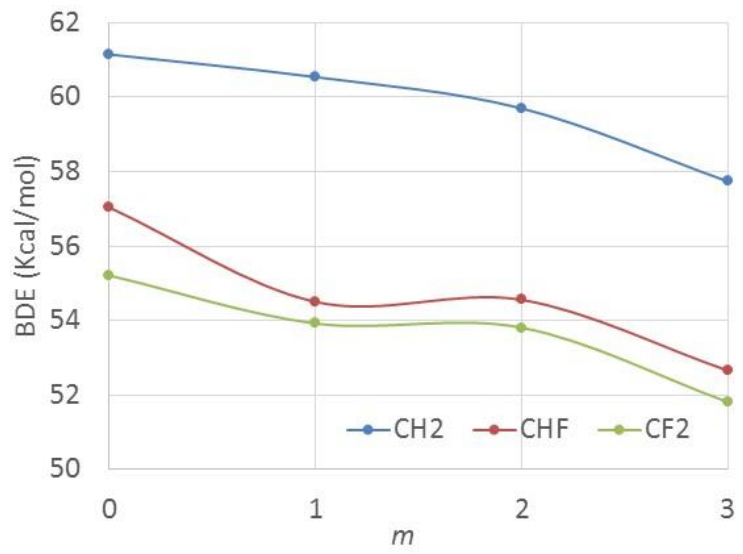

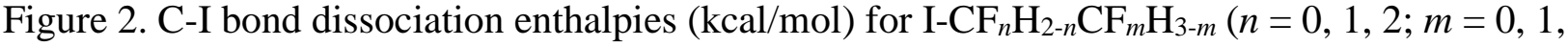
$2,3)$.

The main trends are as follows. ( $i$ ) The absolute BDE values (in the $52-61 \mathrm{kcal} / \mathrm{mol}$ range) are much smaller than for the corresponding C-H bonds $96-105 \mathrm{kcal} / \mathrm{mol}$ ). (ii) Introduction of the first $\mathrm{F}$ atom on the $\mathrm{C}^{\alpha}$ atom results in a $4-6 \mathrm{kcal} / \mathrm{mol}$ weakening of the $\mathrm{I}-\mathrm{C}$ bond, just like for the corresponding $\mathrm{H}-\mathrm{C}$ bonds. However, introduction of the second $\mathrm{F}$ atom induces a further slight bond weakening (by $0.3-1.8 \mathrm{kcal} / \mathrm{mol}$ ), whereas the same modification yields a slight bond strengthening (by $0.6-2.4 \mathrm{kcal} / \mathrm{mol}$ ) for the corresponding $\mathrm{C}-\mathrm{H}$ bonds. (iii) The progressive $\mathrm{H} / \mathrm{F}$ substitution on the 
$\mathrm{C}^{\beta}$ atom causes a bond weakening, contrarily to the effect on the corresponding H-C BDE. Like for the $\mathrm{R}-\mathrm{H}$ molecules, the BDE variation as $m$ increases is monotonous for the molecules generating the $\mathrm{CH}_{2}$ radical $(n=0)$ and non-monotous for the other two series $(n=1,2)$.

\section{(c) BDE of the R-SC(S)OMe bonds.}

The $\mathrm{X}-\mathrm{CH}_{2-n} \mathrm{~F}_{n} \mathrm{CH}_{3-m} \mathrm{~F}_{m}$ molecules with $\mathrm{X}=$ xanthate are models of dormant chains in RAFT polymerization. While the most often used xanthate contains the OEt group, the calculations were carried out on the simpler OMe for computational efficiency, since the electronic and steric properties of OMe and OEt are quite similar. The full results are provided in the SI (Table S5) and the BDEs are summarized in Figure 3. For this family of compounds, the D3 correction for the dispersion forces is even more important than for the R-H and R-I series, leading to an increase of the BDE values that ranges from 3.5 to $4.4 \mathrm{kcal} / \mathrm{mol}$. To the best of our knowledge, there are no experimental data to benchmark these calculations. Like for the two R-H and R-I compound families described above, the xanthate group also binds more strongly to $\mathrm{C}^{\alpha} \mathrm{H}_{2}$ and the bond weakens upon introducing $\alpha \mathrm{F}$ atoms. Also, the $\mathrm{BDE}$ is little affected by the second $\alpha \mathrm{H} / \mathrm{F}$ substitution. In this case, however, also the $\beta \mathrm{F} / \mathrm{H}$ substitution has very little effect.

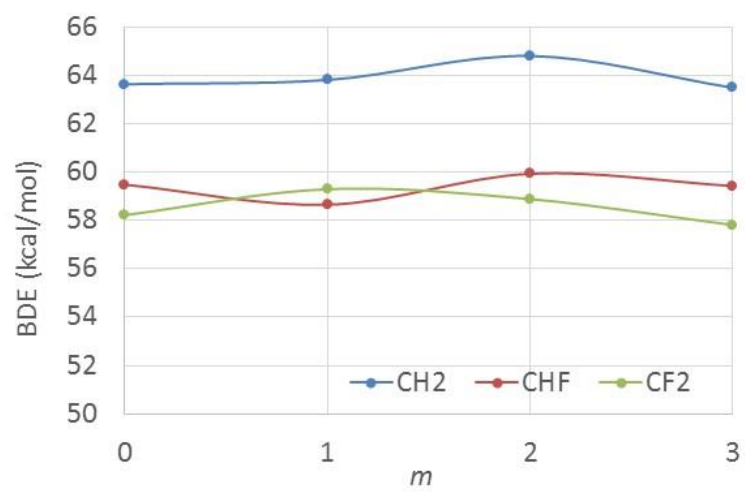

Figure 3. C-S bond dissociation enthalpies (kcal/mol) for $\mathrm{MeOC}(\mathrm{S}) \mathrm{S}-\mathrm{CF}_{n} \mathrm{H}_{2-n} \mathrm{CF}_{m} \mathrm{H}_{3-m}(n=0,1,2$; $m=0,1,2,3)$.

(d) BDE of the R-Co(acac) 2 bonds. 
$\mathrm{Co}(\mathrm{acac})_{2}$ has proven an excellent mediating agent for the OMRP of unreactive monomers, including $\mathrm{C}_{2} \mathrm{H}_{4}$ (though only in combination with vinyl acetate) [17], thus yielding dormant chains of type (acac) $)_{2} \mathrm{Co}-\mathrm{CH}_{2} \mathrm{CH}_{2}$-polymer. The BDEs of $(\mathrm{acac})_{2} \mathrm{Co}-\mathrm{CH}_{2-n} \mathrm{~F}_{n} \mathrm{CH}_{3-m} \mathrm{~F}_{m}$ are therefore of interest for the possible OMRP of fluorinated monomers such as VDF and TrFE. The moderating agent $\mathrm{Co}(\mathrm{acac})_{2}$ has a spin quartet ground state with a tetrahedral geometry, while the spin doublet state is at a higher energy and adopts a square planar geometry [36]. Although low spin $\mathrm{d}^{6} \mathrm{Co}^{\mathrm{III}}$ prefers to adopt a six-coordinate geometry, 5 -coordinate (acac) ${ }_{2} \mathrm{Co}-\mathrm{R}$ dormant species with a square pyramidal geometry are obtained when the OMRP is conducted in bulk monomer (no coordinating solvent) and in the absence of the chelating assistance by monomer substituents [37]. The results are listed in Table S6 and the BDEs are displayed in Figure 4. In this case, as may be expected from the greater size of the system and number of van der Waals interactions, the D3 correction is even more substantial than in the previous cases, with the BDEs increasing by an amount in the rather narrow 10.4-11.0 kcal/mol range. The trend for the $\alpha \mathrm{H} / \mathrm{F}$ substitution is strikingly different than those shown in the previous sections. In the present case, the Co-C BDE strengthens upon introducing $\alpha \mathrm{F}$ atoms, especially on going from the $\mathrm{C}^{\alpha} \mathrm{HF}$ to the $\mathrm{C}^{\alpha} \mathrm{F}_{2}$ group. The $\beta \mathrm{H} / \mathrm{F}$ substitution also leads to a bond strengthening. Hence, the BDE of (acac) ${ }_{2} \mathrm{Co}-\mathrm{CH}_{2} \mathrm{CH}_{3}(21.8 \mathrm{kcal} / \mathrm{mol})$, model of the dormant species for the OMRP of ethylene, is the lowest in this series of compunds, whereas that of $\mathrm{I}-\mathrm{CH}_{2} \mathrm{CH}_{3}$ is the highest within the family of ITP dormant chain models (Figure 2).

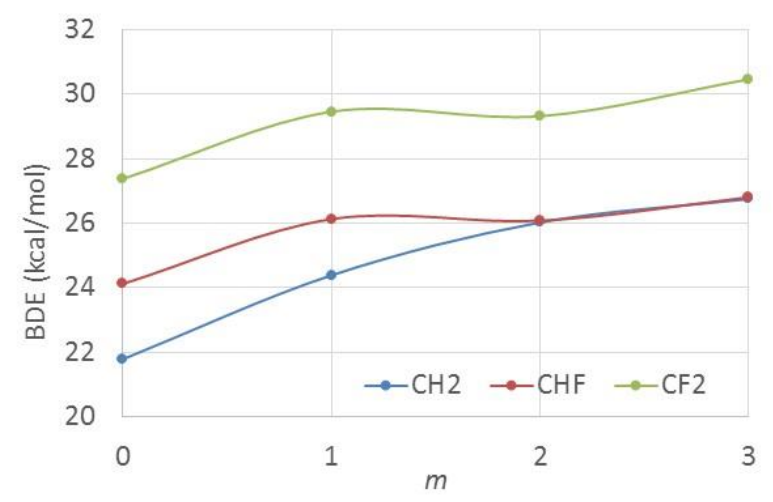

Figure 4. C-Co bond dissociation enthalpies $(\mathrm{kcal} / \mathrm{mol})$ for $(\mathrm{acac})_{2} \mathrm{Co}_{-} \mathrm{CF}_{n} \mathrm{H}_{2-n} \mathrm{CF}_{m} \mathrm{H}_{3-m}(n=0,1,2$; $m=0,1,2,3)$. 


\section{(e) BDE of the R-Mn(CO)s bonds.}

$\mathrm{Mn}(\mathrm{CO})_{5}$ has not been reported as an OMRP mediator. However, its possible implication as radical trapping species in the ITP of VDF $[18,19]$ may be questioned (see Introduction). The results obtained for the family of $(\mathrm{CO})_{5} \mathrm{Mn}-\mathrm{CH}_{2-n} \mathrm{~F}_{n} \mathrm{CH}_{3-m} \mathrm{~F}_{m}$ molecules are collected in Table $\mathrm{S} 7$ and the BDEs are summarized in Figure 5. The trend in this case is more or less the same as for the organometallic analogues with $\mathrm{Co}(\mathrm{acac})_{2}$ (previous section), although the BDEs are greater (in the $42-54 \mathrm{kcal} / \mathrm{mol} \mathrm{range}, v s$. the $22-31 \mathrm{kcal} / \mathrm{mol}$ range for the $\mathrm{Co}(\mathrm{acac})_{2}$ family). The $\mathrm{D} 3$ correction is greater than that for the xanthate series but smaller than that for the $\mathrm{Co}(\mathrm{acac})_{2}$ series, in the rather narrow 7.2-7.9 $\mathrm{kcal} / \mathrm{mol}$ range.

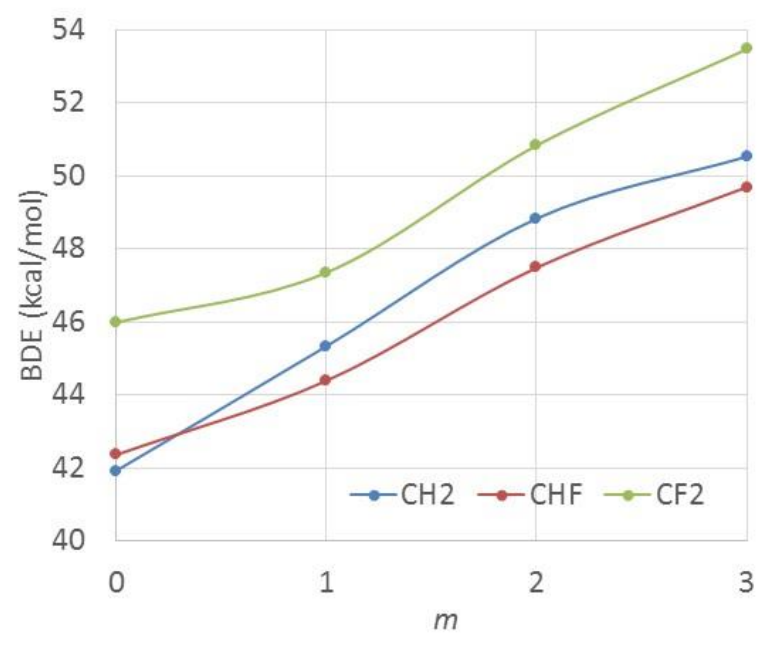

Figure 5. C-Mn bond dissociation enthalpies $(\mathrm{kcal} / \mathrm{mol})$ for $(\mathrm{CO})_{5} \mathrm{Mn}-\mathrm{CF}_{n} \mathrm{H}_{2-n} \mathrm{CF}_{m} \mathrm{H}_{3-m}(n=0,1$, $2 ; m=0,1,2,3)$.

There are only few and rather imprecise experimental BDE determinations for compounds closely related to those reported here $[38,39]$. The $\mathrm{BDE}$ in $(\mathrm{CO})_{5} \mathrm{Mn}-\mathrm{CH}_{3}$ and $(\mathrm{CO})_{5} \mathrm{Mn}-\mathrm{CF}_{3}$, determined by Calvet microcalorimetry, were first reported as $153 \pm 5$ and $172 \pm 7 \mathrm{~kJ} / \mathrm{mol}(36.6 \pm 1.2$ and $41.1 \pm 1.7$ $\mathrm{kcal} / \mathrm{mol})$ [38] and later re-evaluated as $187 \pm 4$ and $203 \pm 6 \mathrm{~kJ} / \mathrm{mol}(44.7 \pm 1.0$ and $48.5 \pm 1.4 \mathrm{kcal} / \mathrm{mol})$ [39]. The re-evaluation is related to the estimation of the $\mathrm{BDE}$ of the $\mathrm{Mn}-\mathrm{Mn}$ bond in $\mathrm{Mn}_{2}(\mathrm{CO})_{10}$, needed in the R-Mn BDE calculation through a thermodynamic cycle. An independent BDE determination for compounds $(\mathrm{CO})_{5} \mathrm{Mn}-\mathrm{CH}_{3},(\mathrm{CO})_{5} \mathrm{Mn}-\mathrm{CH}_{2} \mathrm{~F},(\mathrm{CO})_{5} \mathrm{Mn}-\mathrm{CHF}_{2}$ and $(\mathrm{CO})_{5} \mathrm{Mn}-\mathrm{CF}_{3}$ 
by photoionization mass spectrometry gave values affected by large uncertainties: $192 \pm 11,139 \pm 11$, $144 \pm 11$ and $182 \pm 11 \mathrm{~kJ} / \mathrm{mol}(44.9,33.2,34.4$ and $43.5 \mathrm{kcal} / \mathrm{mol}$, all \pm 2.6$)$, respectively [39]. Curiously, while the calorimetric and photoionization values are in relatively good agreement for the $\mathrm{CH}_{3}$ system (187 vs. $192 \mathrm{~kJ} / \mathrm{mol}$, the difference being smaller than the uncertainty), they are quite different for the $\mathrm{CF}_{3}$ system (203 vs. $182 \mathrm{~kJ} / \mathrm{mol}$ ). In order to assess these values, the computational investigation was extended to these molecules. The related results, also summarized in Table S7, indicate that the calculated BDE of $(\mathrm{CO})_{5} \mathrm{Mn}-\mathrm{CH}_{3}(46.5 \mathrm{kcal} / \mathrm{mol})$ is in close agreement with the re-evaluated calorimetric value and with the mass spectrometry value, being higher than these values by less than $2 \mathrm{kcal} / \mathrm{mol}$. The calculated $\mathrm{BDE}$ of $(\mathrm{CO})_{5} \mathrm{Mn}-\mathrm{CF}_{3}(55.1 \mathrm{kcal} / \mathrm{mol})$, on the other hand, is much higher than all the reported values. It is also worth noting that the trend in the $(\mathrm{CO})_{5} \mathrm{Mn}-\mathrm{CF}_{n} \mathrm{H}_{3-n}$ series $(46.5,45.8,48.0$ and $55.1 \mathrm{kcal} / \mathrm{mol}$, respectively) features, like in the (CO) ${ }_{5} \mathrm{Mn}-\mathrm{CF}_{n} \mathrm{H}_{2-n} \mathrm{CF}_{m} \mathrm{H}_{3-m}$ series with constant $m$, a small BDE decrease upon introducing the first F atom, followed by an increase as $n$ increases. All these values, except for $n=0$, are much higher that those experimentally determined by mass spectrometry, although the trend is the same.

\section{Discussion}

\section{(a) Analysis of the BDE trends}

The effect of the $\mathrm{H} / \mathrm{F}$ substitution at the $\alpha$ and/or $\beta$ positions on the BDE of R-X bonds has not been previously analyzed in detail, except for the R-H series [29]. However, the BDE analysis for this series of compounds was restricted to a qualitative description of the trends and to the suggestion that the $\mathrm{C}-\mathrm{H}$ bond is stabilized by inductive effects, though exceptions were noted. The present contribution reports the analysis of five full series of $\mathrm{X}_{-} \mathrm{CF}_{n} \mathrm{H}_{2-n} \mathrm{CF}_{m} \mathrm{H}_{3-m}$ compounds with $\mathrm{X}=\mathrm{H}$, I, SC(S)OMe, $\mathrm{Co}(\mathrm{acac})_{2}$ and $\mathrm{Mn}(\mathrm{CO})_{5}$. The observed effect is strikingly different depending on the nature of $\mathrm{X}$. In terms of the $\alpha \mathrm{H} / \mathrm{F}$ substitution, two subsets of compounds can be distinguished. In the first one, comprising the three series with $\mathrm{X}=\mathrm{H}$, I and $\mathrm{SC}(\mathrm{S}) \mathrm{OMe}$, the first $\alpha \mathrm{F}$ atom leads to significant bond weakening, whereas the second $\alpha \mathrm{F}$ atom induces a smaller BDE change: 
strengthening for $\mathrm{X}=\mathrm{H}$ but weakening for $\mathrm{X}=\mathrm{I}$ and $\mathrm{SC}(\mathrm{S}) \mathrm{OMe}$, slightly modulated by the $\beta \mathrm{H} / \mathrm{F}$ substitution. On the other hand, in the second subset with $\mathrm{X}=\mathrm{Co}(\mathrm{acac})_{2}$ and $\mathrm{Mn}(\mathrm{CO})_{5}$ the first $\alpha \mathrm{F}$ atom has a small effect while the second one has a strong strenthening effect. Overall, the most remarkable difference between the various families is that the $\mathrm{X}-\mathrm{C} \mathrm{BDE}$ is strongest for $n=0\left(\mathrm{C}^{\alpha} \mathrm{H}_{2}\right)$ when $\mathrm{X}=\mathrm{H}$, I and SC(S)OMe and for $n=2\left(\mathrm{C}^{\alpha} \mathrm{F}_{2}\right)$ when $\mathrm{X}=\mathrm{Co}(\operatorname{acac})_{2}$ and $\mathrm{Mn}(\mathrm{CO})_{5}$. Within each $\mathrm{X}-\mathrm{CF}_{n} \mathrm{H}_{2-n} \mathrm{CF}_{m} \mathrm{H}_{3-m}$ series with constant $\mathrm{X}$ and $n$, the $\beta \mathrm{H} / \mathrm{F}$ substitution leads to progressive bond strengthening for $\mathrm{X}=\mathrm{H}$ and for the two organometallic series, to bond weakening for $\mathrm{X}=\mathrm{I}$, and to nearly no effect for $\mathrm{X}=\mathrm{SC}(\mathrm{S}) \mathrm{OMe}$, with these changes being somewhat modulated by $n$.

Whereas a full rationalization of these trends will not be possible, a few considerations may be offered on the basis of the bond analysis in terms of the contributions of covalency (orbital interaction) and polarity (charge separation) [40]. The covalent component is influenced by various factors. Two of them are the orbital overlap and the energy matching between the interacting orbitals of the two participating fragments in the prepared geometry - i.e. the same geometry as in the final molecule. These contributions may be influenced by the substituents inductive effects. Another factor is the steric effects related to the "preparation" of the two fragments from their relaxed geometries. However, an analysis of the geometrical parameters (Table S8) and relaxation energies of the $\mathrm{CF}_{n} \mathrm{H}_{2-n} \mathrm{CF}_{m} \mathrm{H}_{3-m}$ radicals (a comparison for $\mathrm{X}=\mathrm{H}$ and $\mathrm{Mn}(\mathrm{CO})_{5}$ is reported in Table S9) indicates that this effect is small and cannot rationalize the observed trends. A final contribution to the covalent component of the bond strength is the electron density redistribution of the unpaired electron during the fragments preparation. The data (Table S10) suggest, however, that this also contribute to a negligible extent to the BDEs. For a more detailed analysis of the steric and spin redistribution contributions, see the Supporting Information.

The polar contribution is related to the Coulombic cost associated to the charge redistribution that occurs along the bond breaking process. This contribution can be assessed from the analysis of the effective charges (q) on the two separated atoms that are involved in the bond, namely $q(C)$ and $q(E)$, where $E$ stands for the element of the $X$ group bonded to the $\mathrm{C}^{\alpha}$ atom $(H, I, S$ for the xanthate, 
Co for $\mathrm{Co}(\mathrm{acac})_{2}$, and $\mathrm{Mn}$ for $\left.\mathrm{Mn}(\mathrm{CO})_{5}\right)$. The charge difference $\Delta \mathrm{q}(\mathrm{E}-\mathrm{C})=\mathrm{q}(\mathrm{E})_{\mathrm{R}-\mathrm{X}}-\mathrm{q}(\mathrm{C})_{\mathrm{R}-\mathrm{X}}$ is the bond polarity, which may be either positive or negative, and the polarity change upon bond formation is defined as $\Delta \Delta \mathrm{q}=\Delta \mathrm{q}(\mathrm{E}-\mathrm{C})-\left[\mathrm{q}(\mathrm{E})_{\mathrm{X} \text {,free }}-\mathrm{q}(\mathrm{C})_{\mathrm{R} \text {,free }}\right]$. A non-zero $\Delta \Delta \mathrm{q}$, in whichever direction, corresponds to a Coulombic gain and to a stronger ionic component to the BDE. In other terms, when viewed along the reverse bond breaking process, the $-\Delta \Delta \mathrm{q}$ change is associated to the energy cost of the charge redistribution needed to prepare to two elements for the covalent bond cleavage. A positive $\Delta \Delta \mathrm{q}$ means that the bond formation increases the positive charge (or decreases the negative charge) on $\mathrm{E}$ and increases the negative charge (or decreases the positive charge) on $\mathrm{C}^{\alpha}$. Both Mulliken charges and natural charges obtained by a Natural Bond Orbital (NBO) calculation were used for the analysis. The list of relevant charges and the values of the $\Delta \mathrm{q}(\mathrm{E}-\mathrm{C})$ and $\Delta \Delta \mathrm{q}$ parameters (Table S11 for the Mulliken analysis and Table S12 for the NBO analysis), as well as a detailed analysis of the various trends (Figures S2-S16) are provided in the SI.

As a short summary of the most relevant points, both the Mulliken and the NBO analyses provide the same qualitative trends, although the absolute $\Delta \mathrm{q}(\mathrm{E}-\mathrm{C})$ and $\Delta \Delta \mathrm{q}$ values differ. For all the series of $\mathrm{X}_{-}-\mathrm{CF}_{n} \mathrm{H}_{2-n} \mathrm{CF}_{m} \mathrm{H}_{3-m}$ molecules, $\Delta \Delta \mathrm{q}$ increases as $n$ decreases $\left(\mathrm{C}^{\alpha} \mathrm{F}_{2}<\mathrm{C}^{\alpha} \mathrm{HF}<\mathrm{C}^{\alpha} \mathrm{H}_{2}\right)$ and as $m$ increases $\left(\mathrm{C}^{\beta} \mathrm{H}_{3}<\mathrm{C}^{\beta} \mathrm{FH}_{2}<\mathrm{C}^{\beta} \mathrm{F}_{2} \mathrm{H}<\mathrm{C}^{\beta} \mathrm{F}_{3}\right)$. However, the salient point is that the $\Delta \Delta \mathrm{q}$ values are positive for all values of $n$ and $m$ when $\mathrm{X}=\mathrm{H}$, I and SC(S)OMe (with only three exceptions for the SC(S)OMe series, where small negative values are obtained, though only from the Mulliken analysis), whereas they are all negative when $\mathrm{X}=\mathrm{Co}(\mathrm{acac})_{2}$ and $\mathrm{Mn}(\mathrm{CO})_{5}$. Therefore, the contribution of the charge redistribution to the ionic component of the $\mathrm{BDE}$ is greater for the $\mathrm{C}^{\alpha} \mathrm{H}_{2}$ series within the first group of compounds with $\mathrm{H}$, I or $\mathrm{SC}(\mathrm{S}) \mathrm{OMe}$, and greater for the $\mathrm{C}^{\alpha} \mathrm{F}_{2}$ series within the two organometallic families. These trends perfectly match those of the calculated BDEs, leading to the suggestion that this invertion is probably mostly determined by polar effects. The other BDE trends, however, are not reproduced by the $\Delta \Delta \mathrm{q}$ values. One of the discrepancies is the inversion between the $\mathrm{C}^{\alpha} \mathrm{HF}$ and $\mathrm{C}^{\alpha} \mathrm{F}_{2}$ series for $\mathrm{X}=\mathrm{H}$, whereas the $\Delta \Delta \mathrm{q}$ parameter shows a more regular and monotonous change as a function of $n$. Another discrepancy is between the BDE and 
$\Delta \Delta \mathrm{q}$ trends as a function of $m$. The BDE values evolve according to the $\Delta \Delta \mathrm{q}$ prediction when $\mathrm{X}=$

$\mathrm{H}$ (particularly the $n=0$ series) and in the opposite direction for the $\mathrm{I}, \mathrm{Co}(\mathrm{acac})_{2}$ and $\mathrm{Mn}(\mathrm{CO})_{5}$ series. The probable reason is that the variations of $\Delta \Delta \mathrm{q}$ are smaller, particularly as a function of $m$, thus the effects on the covalent component of the bond strength overshadow those on the polar one.

A full rationalization of all BDE trends would require a deeper analysis of the covalent component of the $\mathrm{X}-\mathrm{C}^{\alpha}$ bonds for all $\mathrm{H} / \mathrm{F}$ substitution patters and $\mathrm{X}$ groups. Since, as discussed above, steric effects and spin density redistribution cannot rationalize the observed trends, the BDE variations must result from the $\mathrm{H} / \mathrm{F}$ influence on the fragment orbitals overlap and energy matching. For instance, infrared spectroscopy has provided evidence for a $\pi$ interaction between $\mathrm{Mn}(\mathrm{CO})_{5}$ and the $\mathrm{CF}_{3}$ group, but no quantification in terms of contribution to the BDE or extension to other fluorinated alkyl derivatives have been presented to the best of our knowledge [41]. Such an analysis is beyond the scope of the present investigation.

\section{(b) Relevance for the controlled polymerization of fluorinated monomers}

The BDE trends can be analyzed in relation with the experimentally known behaviour in the RDRP of VDF and certain predictions in terms of the RDRP of other monomers may be made. It should first be noted that RAFT and ITP are degenerative transfer methods. The dormant chains are reactivated by associative radical exchange. Thus, the absolute BDE values are irrelevant [42]. The BDE difference between isomeric chains, however, is relevant because the stronger bond will not be reactivated easily by exchange with the radical that forms the weaker bond (this exchange is nondegenerate and endothermic), causing a problem when the latter radical is dominant in solution. The OMRP mediated by $\mathrm{Co}(\mathrm{acac})_{2}$ can operate either by degenerate transfer, because of an available open coordination site, or by reversible termination when this site is blocked by an additional ligand. Reversible termination methods act by reversible cleavage of the bond between the polymer chain and the moderating agent, thus the absolute BDE value is of crucial importance. Coordinatively 
saturated metal complexes such as $\mathrm{R}-\mathrm{Mn}(\mathrm{CO})_{5}$ may only operate by the reversible termination strategy.

Starting the analysis with the ITP of VDF, if $\mathrm{I}_{-} \mathrm{CF}_{2} \mathrm{CH}_{3}$ and $\mathrm{I}-\mathrm{CH}_{2} \mathrm{CF}_{2} \mathrm{H}$ are considered as good models of the dormant chains generated after the normal monomer addition ( $\mathrm{I}-\mathrm{CF}_{2} \mathrm{CH}_{2}-\mathrm{PVDF}$ or I$\left.\mathrm{PVDF}_{\mathrm{H}}\right)$ and the inverted monomer addition $\left(\mathrm{I}-\mathrm{CH}_{2} \mathrm{CF}_{2}-\mathrm{PVDF}\right.$ or I-PVDF $)$, respectively, the calculations are consistent with the experimentally observed more difficult reactivation of the latter [3], since the BDE is $4.5 \mathrm{kcal} / \mathrm{mol}$ greater. Trifluoroethylene (TrFE) is another asymmetric monomer of interest, for which the ITP has only been claimed in a patent [43]. It is known to have a higher probability of reverse addition than $\operatorname{VDF}(14 \%)[44,45]$. This monomer gives dormant chains of type $\mathrm{I}-\mathrm{CF}_{2} \mathrm{CHF}-\mathrm{PTrFE}$ (normal) and $\mathrm{I}_{-} \mathrm{CHFCF}_{2}-\mathrm{PTrFE}$ (inverted); the BDEs of the model compounds $\mathrm{I}_{-} \mathrm{CF}_{2} \mathrm{CH}_{2} \mathrm{~F}$ and $\mathrm{I}-\mathrm{CHFCHF}_{2}$ are computed as 53.9 and $54.6 \mathrm{kcal} / \mathrm{mol}$, respectively. With a difference of only $0.7 \mathrm{kcal} / \mathrm{mol}$ in favour of the reactivation of the regular dormant chain, one could predict that the TrFE polymerization should be better controlled than that of VDF. Finally, it may be noted that the bond in $\mathrm{I}-\mathrm{CH}_{2} \mathrm{CH}_{3}$, a model for the dormant chain in the ITP of ethylene, is predicted as stronger than those with fluorinated chains (Figure 2). However, since ITP is an associative exchange method and the monomer is symmetric, it should be possible [42] to envisage a controlled polymerization of ethylene by ITP.

The experimental results in the RAFT polymerization of VDF using xanthate transfer agents are quite similar to those obtained by ITP, with the $\mathrm{PVDF}_{\mathrm{T}}$-xanthate dormant chains being reactivated more slowly than the $\mathrm{PVDF}_{\mathrm{H}-\mathrm{X} a n t h a t e}$ ones and accumulating in the medium as the polymerization progresses. This limits the access to high molecular weight polymers [13]. The computed BDEs are again in agreement, since the inverted chain end model $\mathrm{MeOC}(\mathrm{S}) \mathrm{S}-\mathrm{CH}_{2} \mathrm{CF}_{2} \mathrm{H}$ has a $\mathrm{BDE} 4.6$ $\mathrm{kcal} / \mathrm{mol}$ greater than the normal chain end one $\mathrm{MeOC}(\mathrm{S}) \mathrm{S}-\mathrm{CF}_{2} \mathrm{CH}_{3}$ (Figure 3). The $\mathrm{BDE}$ differences between normal and inverted chain ends with $\mathrm{X}=\mathrm{I}$ and SC(S)OMe are essentially the same and indeed ITP and RAFT perform quite similarly in the controlled polymerization of this monomer. Like in ITP, the polymerization of TrFE by RAFT is predicted to be better controlled, 
because the inverted chain end model has a BDE only $0.6 \mathrm{kcal} / \mathrm{mol}$ greater than the normal chain end model. Finally, the BDE in the polyethylene dormant chain model, $\mathrm{MeOC}(\mathrm{S}) \mathrm{S}-\mathrm{CH}_{2} \mathrm{CH}_{3}$ is quite close to that of the $\mathrm{PVDF}_{\mathrm{T}}-\mathrm{SC}(\mathrm{S}) \mathrm{OMe}$ model, but this high strength does not affect the controlled polymerization of ethylene because this monomer is symmetric. Indeed, the RAFT polymerization of ethylene has recently been achieved, although control is negatively affected by side reactions, such as addition of a PE radical chain to the intermediate symmetric PE-S-C $(\mathrm{OEt})-\mathrm{S}-\mathrm{PE}$ radical, or fragmentation of the latter to yield PE-S-C(O)-S-PE [46].

For the $\mathrm{Co}(\mathrm{acac})_{2}$-mediated OMRP, the BDE trend is opposite, with the introduction of $\alpha \mathrm{F}$ atoms strengthening the bond in the dormant species. The BDE of (acac) ${ }_{2} \mathrm{Co}-\mathrm{CH}_{2} \mathrm{CH}_{3}(21.8 \mathrm{kcal} / \mathrm{mol})$, a model of the polyethylene dormant chain, is lower than those of all other dormant chain models containing $\mathrm{F}$ atoms either in the $\alpha$ or in the $\beta$ position (Figure 4). Experimentally, the OMRP of an ethylene-VAc mixture is well controlled under reversible termination conditions, with a reasonable polymerization rate at $40^{\circ} \mathrm{C}$ [17], meaning that the (acac) $)_{2} \mathrm{Co}_{-} \mathrm{CH}_{2} \mathrm{CH}_{2}-(\mathrm{PE}-\mathrm{co}-\mathrm{PVAc})$ chain ends can be dissociatively reactivated, i.e. without excess radicals. The BDE of the $\mathrm{Co}-\mathrm{C}$ bond in these dormant species is presumably close to that of (acac) $)_{2}$ Co-PE. Thus, the polymerization of fluorinated monomers is predicted to be more difficult if operating by reversible termination, but the dissociative equilibrium may be enhanced at higher temperature if it is too slow at $40{ }^{\circ} \mathrm{C}$. The degenerative transfer strategy does not suffer from the absolute BDE, but still suffers from the BDE difference if the monomer is asymmetric. For VDF, however, the BDE of the dormant chain model after the inverted monomer addition, (acac) ${ }_{2} \mathrm{Co}-\mathrm{CH}_{2} \mathrm{CF}_{2} \mathrm{H},(26.0 \mathrm{kcal} / \mathrm{mol})$, is actually lower than that of the regular dormant chain model, (acac) ${ }_{2} \mathrm{Co}_{-} \mathrm{CF}_{2} \mathrm{CH}_{3}(27.4 \mathrm{kcal} / \mathrm{mol})$. Therefore, no loss of control (and no slowdown of the polymerization rate under reversible termination conditions) can be predicted for the $\mathrm{Co}(\mathrm{acac})_{2}$-mediated OMRP of VDF on the basis of our calculations. Likewise, the $\mathrm{Co}(\mathrm{acac})_{2}$-mediated OMRP of TrFE, although more difficult under reversible termination conditions because the BDEs are greater, should not be negatively affected by inverted monomer additions, because the inverted chain forms a weaker bond $\left(26.1 \mathrm{kcal} / \mathrm{mol}\right.$ for the $(\mathrm{acac})_{2} \mathrm{Co}-$ 
$\mathrm{CHFCHF}_{2}$ model) than the normal chain $\left(29.4 \mathrm{kcal} / \mathrm{mol}\right.$ for the (acac) ${ }_{2} \mathrm{Co}_{-} \mathrm{CF}_{2} \mathrm{CH}_{2} \mathrm{~F}$ model $)$. The polymerization should also proceed smoothly under degenerate transfer conditions.

Finally, we analyze the results of our calculations on the R-Mn(CO) $)_{5}$ molecules (Figure 5). The BDEs of the R-Mn bonds are in a range of much higher values $(42-54 \mathrm{kcal} / \mathrm{mol})$ than those of the R-Co(acac) 2 bonds (22-31 kcal/mol). These hypothetical OMRP dormant species may only operate by the dissociative activation (reversible termination) mechanism because they do not have available sites to allow an associative radical exchange. In terms of the polymerization rate, the more relevant parameter is the bond dissociation free energy (BDFE), $\Delta G_{\text {OMRP, }}$ because the dissociative activation pre-equilibrium is followed by the rate-determining monomer addition to the free radical chain and the overall rate is proportional to the product $K_{\mathrm{OMRP}} \cdot k_{\mathrm{p}}$ (where $K_{\mathrm{OMRP}}$ and $k_{\mathrm{p}}$ stand for the equilibrium constant of the dissociative activation equilibrium, which is given by $\exp (-$ $\left.\Delta G_{\mathrm{OMRP}} / \mathrm{RT}\right)$, and the monomer propagation rate constant, respectively). The BDFEs of the R$\mathrm{Mn}(\mathrm{CO})_{5}$ bonds are in the $28-39 \mathrm{kcal} / \mathrm{mol}$ range (Table S7), with specific values for the $\mathrm{PVDF}_{\mathrm{H}}$ and $\mathrm{PVDF}_{\mathrm{T}}$ dormant chain models of 31.5 and $34.7 \mathrm{kcal} / \mathrm{mol}$, respectively (note that in this case the "inverted" dormant species model has the stronger bond), vs. values in the 7-15 kcal/mol range for the BDFEs of R-Co(acac)2, with specific values for $\mathrm{PVDF}_{\mathrm{H}}$ and $\mathrm{PVDF}_{\mathrm{T}}$ of 12.5 and $11.4 \mathrm{kcal} / \mathrm{mol}$. Just focusing on the $\mathrm{PVDF}_{\mathrm{H}}$ models, the $\Delta G_{\mathrm{OMRP}}$ values yield $K_{\mathrm{OMRP}}\left(\mathrm{Mn}(\mathrm{CO})_{5}\right) / K_{\mathrm{OMRP}}\left(\mathrm{Co}(\mathrm{acac})_{2}\right)$ $=1.2 \cdot 10^{-14}$ at $298 \mathrm{~K}$. Even by operating at $398 \mathrm{~K}\left(125^{\circ} \mathrm{C}\right), K_{\mathrm{OMRP}}\left(\mathrm{Mn}(\mathrm{CO})_{5}\right)$ is still quite small $\left(5.2 \cdot 10^{-18}\right)$, whereas $K_{\mathrm{OMRP}}\left(\mathrm{Co}(\mathrm{acac})_{2}\right)$ at $298 \mathrm{~K}$ is calculated as $6.9 \cdot 10^{-10}$. The "inverted" dormant chains $\mathrm{PVDF}_{\mathrm{T}}-\mathrm{Mn}(\mathrm{CO})_{5}$ would be reactivated even more slowly. These numbers allow to predict that, if the PVDF-Mn $(\mathrm{CO})_{5}$ chains are formed during the $\mathrm{Mn}_{2}(\mathrm{CO})_{10}$-assisted ITP of VDF (see Introduction), which was conducted at $40{ }^{\circ} \mathrm{C}$, they would not be thermally reactivated at significant rates during the polymerization. The investigation of the PVDF-I polymers recovered from the $\mathrm{Mn}_{2}(\mathrm{CO})_{10}$-assisted ITP process gave no evidence for the presence of $\mathrm{Mn}(\mathrm{CO})_{5}$-containing chain ends [18]. This means that either these chains are not formed for kinetic reasons, or if they do they 
are reactivated under the photolytic conditions used in the polymer synthesis. The present study, however, supports the notion that they cannot be rapidly activated under thermal conditions.

\section{Conclusion}

This study highlights different trends for the $\mathrm{BDE}$ of $\mathrm{X}-\mathrm{CF}_{n} \mathrm{H}_{2-n} \mathrm{CF}_{m} \mathrm{H}_{3-m}$ compounds, some of which are models of dormant species in the controlled polymerization of ethylene and of certain fluorinated olefins by ITP $(\mathrm{X}=\mathrm{I})$, RAFT $(\mathrm{X}=\mathrm{SC}(\mathrm{S}) \mathrm{OMe})$ and OMRP $\left(\mathrm{X}=\mathrm{Co}(\mathrm{acac})_{2}\right)$. The investigation has also included the related compounds with $\mathrm{X}=\mathrm{H}$, for the purpose of benchmarking the computational method, and with $\mathrm{X}=\mathrm{Mn}(\mathrm{CO})_{5}$ because of the potential involvement of $(\mathrm{CO})_{5} \mathrm{Mn}-\mathrm{PVDF}$ species in the ITP of VDF. The most interesting insight is that the introduction of $\alpha \mathrm{F}$ atoms weakens the $\mathrm{X}-\mathrm{C}$ bond for $\mathrm{X}=\mathrm{H}$, I and $\mathrm{SC}(\mathrm{S}) \mathrm{OMe}$ but strengthens it for $\mathrm{X}=\mathrm{Co}(\mathrm{acac})_{2}$ or $\mathrm{Mn}(\mathrm{CO})_{5}$. Within the first group, the weakening effect is more notable when $n$ goes from 0 to 1 , whereas in the second one the strengthening effect is more notable when $n$ goes from 1 to 2 . The orientation of the bond dipole and its influence on the ionic component of the $\mathrm{X}-\mathrm{C}$ bond appears the key to rationalize this trend inversion. Other trends, such as the BDE changes following the introduction of $\beta \mathrm{F}$ atoms, on the other hand, do not correlate with the bond polarity and can therefore be attributed to the effect of the H/F substitution on the covalent component of the bond energy. The BDE trends calculated for $\mathrm{X}=\mathrm{I}$ and $\mathrm{SC}(\mathrm{S}) \mathrm{OMe}$ rationalize experimental observations made in the ITP and RAFT polymerizations of VDF, notably the accumulation of less easily reactivatable dormant species, $\mathrm{PVDF}_{\mathrm{T}} \mathrm{X}$, generated after an inverted monomer addition. The opposite trend for the transition metal systems (stronger bonds with more $\mathrm{F}^{\alpha}$-substituted alkyl groups) is in qualitative agreement with the notion that organometallic compounds with perfluorinated alkyls are generally more stable than their non-fluorinated counterparts, but experimental BDE determinations have been very limited and affected by large uncertainties [39]. 
These results bode well for the development of efficient controlled polymerizations of fluorinated monomers based on OMRP.

\section{Acknowledgements}

The authors geratefully acknowledge financial support of the Agence Nationale de la Recherche (ANR, project FLUPOL, contrat No. ANR-14-CE07-0012). This work was granted access to the HPC resources of IDRIS under the allocation 2016-086343 made by GENCI (Grand Equipement National de Calcul Intensif) and to the resources of the CICT (Centre Interuniversitaire de Calcul de Toulouse, project CALMIP).

\section{Supplementary data}

Figures and tables of structural data, thermodynamic data, spin densities, atomic Mulliken and natural charges, Cartesian coordinates, and total energies for all calculated molecules.

\section{References}

[1] B. Ameduri, H. Sawada, Fluorinated Polymers: From Fundamental to Practical Synthesis and Applications. Volume 1: Synthesis, Properties, Processing and Simulations, Royal Society of Chemistry, Oxford, 2016.

[2] B. Ameduri, H. Sawada, Fluorinated Polymers: From Fundamental to Practical Synthesis and Applications. Volume 2: Applications, Royal Society of Chemistry, Oxford, 2016.

[3] C. Boyer, D. Valade, P. Lacroix-Desmazes, B. Améduri, B. Boutevin, J. Polym. Sci., Polym. Chem., 44 (2006) 5763-5777.

[4] M. Oka, M. Tatemoto, Vinylidene fluoride-hexafluoropropylene copolymer having terminal iodines, in: W.J. Bailey, T. Tsuruta (Eds.) Contemporary Topics in Polymer Science, Plenum Press, New-York, 1984, pp. 763-781.

[5] M. Tatemoto, Int. Polym. Sci. Tech., 12 (1985) 85-98.

[6] M. Tatemoto, T. Shimizu, Thermoplastic Elastomers, in: J. Scheirs (Ed.) Modern Fluoropolymers, Wiley, New-York, 1997, pp. 565-576.

[7] G. Kostov, F. Boschet, J. Buller, L. Badache, S. Brandsadter, B. Améduri, Macromolecules, 44 (2011) 1841-1855.

[8] E. Girard, J.D. Marty, B. Améduri, M. Destarac, Acs Macro Letters, 1 (2012) 270-274.

[9] Y. Patil, B. Améduri, Polym. Chem., 4 (2013) 2783-2799.

[10] M. Guerre, B. Campagne, O. Gimello, K. Parra, B. Ameduri, V. Ladmiral, Macromolecules, 48 (2015) 7810-7822. 
[11] M. Guerre, G. Lopez, T. Soulestin, C. Totee, B. Ameduri, G. Silly, V. Ladmiral, Macromol. Chem. Phys., 217 (2016) 2275-2285.

[12] M. Guerre, M. Uchiyama, E. Folgado, M. Semsarilar, B. Ameduri, K. Satoh, M. Kamigaito, V. Ladmiral, Acs Macro Letters, 6 (2017) 393-398.

[13] M. Guerre, S.M.W. Rahaman, B. Améduri, R. Poli, V. Ladmiral, Macromolecules, 49 (2016) $5386-5396$.

[14] A. Debuigne, J.R. Caille, C. Detrembleur, R. Jerome, Angew. Chem. Int. Ed. Engl., 44 (2005) 3439-3442.

[15] A. Debuigne, J.R. Caille, R. Jérôme, Angew. Chem. Int. Ed. Engl., 44 (2005) 1101-1104.

[16] S. Banerjee, V. Ladmiral, A. Debuigne, C. Detrembleur, S.M.W. Rahaman, R. Poli, B. Améduri, Macromol. Rapid Commun., (2017) 1700203.

[17] A. Kermagoret, A. Debuigne, C. Jerome, C. Detrembleur, Nature Chemistry, 6 (2014) 179-187.

[18] A.D. Asandei, O.I. Adebolu, C.P. Simpson, J. Am. Chem. Soc., 134 (2012) 6080-6083.

[19] C.P. Simpson, O.I. Adebolu, J.-S. Kim, V. Vasu, A.D. Asandei, Macromolecules, 48 (2015) 6404-6420.

[20] M.J. Frisch, G.W. Trucks, H.B. Schlegel, G.E. Scuseria, M.A. Robb, J.R. Cheeseman, G. Scalmani, V.

Barone, B. Mennucci, G.A. Petersson, H. Nakatsuji, M. Caricato, X. Li, H.P. Hratchian, A.F. Izmaylov, J.

Bloino, G. Zheng, J.L. Sonnenberg, M. Hada, M. Ehara, K. Toyota, R. Fukuda, J. Hasegawa, M. Ishida, T.

Nakajima, Y. Honda, O. Kitao, H. Nakai, T. Vreven, J. Montgomery, J. A., J.E. Peralta, F. Ogliaro, M.

Bearpark, J.J. Heyd, E. Brothers, K.N. Kudin, V.N. Staroverov, R. Kobayashi, J. Normand, K. Raghavachari, A. Rendell, J.C. Burant, S.S. Iyengar, J. Tomasi, M. Cossi, N. Rega, N.J. Millam, M. Klene, J.E. Knox, J.B. Cross, V. Bakken, C. Adamo, J. Jaramillo, R. Gomperts, R.E. Stratmann, O. Yazyev, A.J. Austin, R. Cammi, C.

Pomelli, J.W. Ochterski, R.L. Martin, K. Morokuma, V.G. Zakrzewski, G.A. Voth, P. Salvador, J.J.

Dannenberg, S. Dapprich, A.D. Daniels, Ö. Farkas, J.B. Foresman, J.V. Ortiz, J. Cioslowski, D.J. Fox, Gaussian 09, Revision D.01, Gaussian, Inc., Wallingford CT, 2009.

[21] M. Reiher, Inorg. Chem., 41 (2002) 6928-6935.

[22] A.W. Ehlers, M. Böhme, S. Dapprich, A. Gobbi, A. Hoellwarth, V. Jonas, K.F. Koehler, R. Stegmann, A. Veldkamp, G. Frenking, Chem. Phys. Lett., 208 (1993) 111-114.

[23] A. Höllwarth, M. Böhme, S. Dapprich, A. Ehlers, A. Gobbi, V. Jonas, K. Kohler, R. Stegmann, A.

Veldkamp, G. Frenking, Chem. Phys. Lett., 208 (1993) 237-240.

[24] S. Grimme, J. Antony, S. Ehrlich, H. Krieg, J. Chem. Phys., 132 (2010).

[25] Y.H. Chen, A. Rauk, E. Tschuikowroux, J. Chem. Phys., 93 (1990) 1187-1195.

[26] Y.H. Chen, A. Rauk, E. Tschuikowroux, J. Chem. Phys., 93 (1990) 6620-6629.

[27] Y.H. Chen, A. Rauk, E. Tschuikowroux, J. Chem. Phys., 94 (1991) 7299-7310.

[28] Y.H. Chen, A. Rauk, E. Tschuikowroux, J. Chem. Phys., 95 (1991) 2774-2786.

[29] J.M. Martell, R.J. Boyd, Z. Shi, J. Phys. Chem., 97 (1993) 7208-7215.

[30] W.R. Dolbier, Chem. Rev., 96 (1996) 1557-1584.

[31] D.F. McMillen, D.M. Golden, Annual Review of Physical Chemistry, 33 (1982) 493-532.

[32] E.C. Wu, A.S. Rodgers, Int. J. Chem. Kinet., 5 (1973) 1001-1006.

[33] J.M. Pickard, A.S. Rodgers, International Journal of Chemical Kinetics, 8 (1976) 809-815.

[34] E.N. Okafo, E. Whittle, International Journal of Chemical Kinetics, 7 (1975) 287-300.

[35] E.C. Wu, A.S. Rodgers, J. Am. Chem. Soc., 98 (1976) 6112-6115.

[36] S. Maria, H. Kaneyoshi, K. Matyjaszewski, R. Poli, Chem. Eur. J., 13 (2007) 2480-2492.

[37] A. Debuigne, Y. Champouret, R. Jérôme, R. Poli, C. Detrembleur, Chem. Eur. J., 14 (2008) 4046-4059.

[38] J.A. Connor, M.T. Zafaranimoattar, J. Bickerton, N.I. Elsaied, S. Suradi, R. Carson, G. Altakhin, H.A.

Skinner, Organometallics, 1 (1982) 1166-1174.

[39] J.A. Martinho Simões, J.L. Beauchamp, Chem. Rev., 90 (1990) 629-688.

[40] L. Pauling, The Nature of the Chemical Bond, 3rd ed., Cornell University Press, Ithaca, New York, 1960.

[41] F.A. Cotton, R.M. Wing, J. Organomet. Chem., 9 (1967) 511-517.

[42] R. Poli, Chem. Eur. J., 21 (2015) 6988-7001.

[43] B. Améduri, A. Alaaddine, Demande Française $n^{\circ} 12.53838$ du 26 Avril 2012 déposée par Arkema/

I'Ecole Nat. Sup. de Chimie de Montpellier/CNRS ; WO2013/160621 (31 Octobre 2013).

[44] A.J. Lovinger, R.E. Cais, Macromolecules, 17 (1984) 1939-1945.

[45] S.A. Reinsberg, S. Ando, R.K. Harris, Polymer, 41 (2000) 3729-3736. 
[46] C. Dommanget, F. D'Agosto, V. Monteil, Angew. Chem. Int. Ed. Engl., 53 (2014) 6683-6686. 